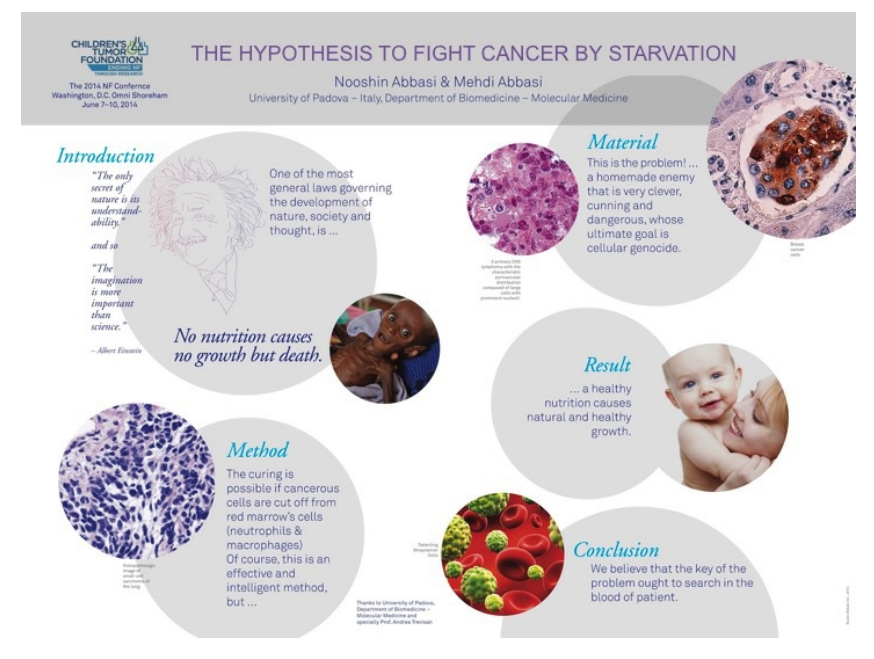

\title{
Could the General Law of Nutrition \& Growth Be also Applicable to Cancer Cells' Growth?
}

Nooshin Abbasi $^{1}$

1 University of Padua

\section{Abstract}

Albert Einstein often used to say "the only secret to nature is its understandability" and so "the imagination is more important than science".

\section{Definitions}

\section{Nutrition and Growth}

Defined by Mehdi Abbasi

INT RODUCTION - The advent and expansion of industries and the pace of industrial productions' development over the past six decades, that is, since the beginning of the second half of the $20^{\text {th }}$ century, especially the increased acceleration which has been occurring in the world in recent decades caused massive pollution of animalistic and plant environment, so that in comparison with past it seems the human beings became more vulnerable than other creatures.

Animals instinctively and because of their physiological necessities feed themselves protectively better than human beings . Moreover, they are accustomed to a single diet 
while human beings use a broad range of foodstuffs containing proteins and vitamins and so on.

In the meantime, rampant poverty and lack of access to healthy and sufficient food, by over one half of world population, or even, rampant consumption of proteins and various beverages by less than one half of the population especially in the West, lead to the different pandemic cancers in recent decades.

It is predicted that by 2020 new cases of cancer will increase and affect from 10 to 15 million people annually. Approximately 8 million people worldwide die of cancer every year ${ }^{[1]}$.

Therefore, collective effort due to solving the problem is of highest significance and is a must.

Heretofore, scientists including biologists, geneticists, chemists, biochemists, physicists and even mathematicians and others have been making efforts in this regard in laboratories, but they have presented no general and comprehensive response for curing the disease .

It seems that the solution of the problem has many reasons, which are absolutely heterogeneous (radioactive radiation, X-ray, UV, poisons, viruses, smoking and air pollution, genetic background, hormonal dysfunction, PVC and polystyrene dishes etc. use of additives in foodstuffs like nitrite and in beverages like sodium benzoate $[2][3][4][5][6][7][8][9])$ and would be totally different of current and usual methods in laboratory.

Albert Einstein often used to say "the only secret to nature is its understandability" and so "the imagination is more important than science". Obviously, by science he meant what was achieved through experiments and testing and not the obvious and unchangeable facts like:

The law of conservation of energy, and the most general laws governing the development of nature, society and thought, especially the law of nutrition and growth which is well considered here by us.

Therefore, the first and most excellent obligation of any science is to determine the relations among phenomena and explain the reasons behind them, because in science what is useless and even might be dangerous is only erroneous experience.

THIS IS THE PROBLEM- Cancerous cells are in fact enemies and invaders that take the control of human's immune system in their own hands.

They first mislead the immune system and make it passive and then beg in to create a complicated arterial network in the tumor. 
This is enabling them to take in as much as oxygen and nutrition from the patient's blood.

This causes cancerous cells proliferate in order to develop their territory in the patient's body. Admittedly, the body and its cells are faced with a homemade enemy that is very clever, cunning and dangerous whose ultimate goal is cellular genocide.

\section{CURRENT METHODS FOR SOLVING THE PROBLEM TILL NOW}

The main solutions which have been offered so far, are as follows:

_ Eliminating tumor using surgery, chemotherapy, radiotherapy.

_ Using vaccines and some poisons like arsenic.

__ Using transplant of fundamental blood maker cells of patient in curing lymphoma.

_ Clinical production of healthy blood from skin of human suffering leukemia for treatment of the disease.

_ Using smart nano-bombs which are able to identify cancerous cells, target and destroy them .

_Exposure of cancerous cells to infrared light at close range in order to heat, cook and destroy them by monoclonal anti - bodies using nano - carbon tubes .

_Photo - thermal meltdown using golden nano - cases which reaches the tumor after injection in bloodstream and then exposing them to UV , causes cancerous cells burn. _ Using photo - dynamic method with the purpose of carrying medicine more accurately via polymer carrier containing nano - particles of iron oxide and directing them with the help of magnetic field from outside the body, without damaging healthy tissues .

_ Using nano - diamond clusters for the purpose of carrying medicine to cancerous cells . _ Using the molecule of an artificial chemical agent which orders the cancerous cells to commit suicide.

_ Finally, interfering with the process of making protein within cells.

With a study of the broad spectrum of methods used to fight cancer ${ }^{[10]}$, we arrive at the conclusion that humanity to this day has only been intimidated by the lethal power of the disease due to its complicated structure and function.

Therefore, it has been trying to find a suitable weapon which would be as unconventional, complicated and sophisticated.

Now, we will see that the main reason behind failure in lab experiments has been the attitude towards the disease .

A DIFFERENT PROCEDURE- As well as formerly a group of American researchers from San Francisco Institute of Biotech and afterwards the researchers of Institute of Karolinska in Sweden showed ${ }^{[11][12]}$, one of the most effective strategic fighting against cancer is to obstruct the formation of new vessels in tumors. 
This is possible if cancerous cells are cut off from red marrow's cells (neutrophils and macrophages), of course, this is an effective and intelligent method, but it should be noted that if we succeed in obstructing the formation of new vessels in the tumor, the blood of patient has remained as a rich source for nutrition of cancerous cells yet. Now the matter can be imagined a better form, hereby, that the first it should be asked, why cancerous cells need to these so much new vessels? Its answer is clear, because they have a hysteric gluttony and for more and faster growth of their colony they need to access a plenty of food which is caring by patient blood. Now, the next question which is crossing one's mind is, what kind of diet these avid cells fond of, whether they eat as same food as healthy cells like it? Or they are eager to an absolutely different food, the food which healthy cells hate it. Therefore, isn't it better to leave it out and send it away of patient blood, after knowing it? Hereby, we will be able to entrap and blockade them in their own place by hunger which is preventing them of growing and developing.

Here is the idea, according to one of the most general laws governing the development of nature, society, and thought, which is the law of nutrition and growth, the quality and quantity of growing depend on the quality and quantity of nutrition. So that a healthy nutrition causes natural and healthy growth and vice versa.

Through this new procedure cancerous cells are trapped perfectly and they have wiped out gradually by themselves and the disease will be cured without any complication. Hence, we believe that the key of the problem ought to search in the blood of patient. Obviously, if diagnosis is taking place before the cancerous cells become metastatic, it could be effective in curing the disease. Otherwise, this procedure could be hopeful too.

\section{ACKNOWLEDGMENT -}

The author would love to thank:

- Mehdi Abbasi (M.Eng.) for giving this brilliant idea and encouraging her to publish this paper;

- Majid Abbasi (designer ${ }^{[13]}$ ) for designing the poster presented at the NF-Conference in Washington D.C. in 2014.

\section{References}

1. ^ http://www.who.int/mediacentre/news/releases/2003/pr27/en/

2. ^ https://www.cancer.gov/about-cancer/causes-prevention/risk/radiation

3. ^ https://www.cancer.org/cancer/cancer-causes/arsenic.htm/

4. ^ https://www.cancer.org/cancer/cancer-causes/infectious-agents/infections-thatcan-lead-to-cancer/viruses.htm/ 
5. ^ http://www.cancerresearchuk.org/about-cancer/causes-of-cancer/smoking-andcancer/how-smoking-causes-cancer

6. ^ https://www.cancer.gov/about-cancer/causes-prevention/genetics

7. ^Brian E. Henderson, Heather Spencer Feigelson. (2000). Hormonal carcinogenesis doi:10.1093/carcin/21.3.427

8. ^ PaulWesley Brandt-Rauf, Changmin Long, Gopala Kovvali, Yongliang Li, Regina Monaco, Marie-Jeanne Marion. (2012). Plastics and carcinogenesis: The example of vinyl chloride J Carcinog, vol. 11 (1), 5. doi:10.4103/1477-3163.93700

9. ^ http://news.bbc.co.uk/2/hi/health/4763528.stm

10. ^Akulapalli Sudhakar. (2009). History of Cancer, Ancient and Modern Treatment Methods J Canc Sci Ther, vol. 01 (02), i-iv. doi:10.4172/1948-5956.100000e2

11. ^ Y. Cao, J. Arbiser, R. J. D'Amato, P. A. D'Amore, D. E. Ingber, R. Kerbel. (2011). FortyYear Journey of Angiogenesis Translational Research Science Translational Medicine, vol. 3 (114), 114rv3-114rv3. doi:10.1126/scitrans/med.3003149

12. ^ https://openarchive.ki.se/xm/ui/bitstream/handle/10616/41539/Thesis_Zhang.pdf? sequence $=6$

13. ^ http://www.studioabbasi.com/ 